\title{
Evaluating regulatory strategies for mitigating hydrological risk in Brazil through diversification of its electricity mix
}

\author{
Maria-Augusta Paim ${ }^{1}$, Arthur R. Dalmarco ${ }^{1,2}$, Chung-Han Yang $^{1,3}$, Pablo Salas ${ }^{1}$, Sören Lindner ${ }^{1,4}$, \\ Jean-Francois Mercure ${ }^{1,4,5,6}$, José Baltazar Salgueirinho Osório de Andrade Guerra ${ }^{1,7}$, Cristiane \\ Derani $^{1,2}$, Tatiana Bruce da Silva ${ }^{8}$ and Jorge E. Viñuales ${ }^{1}$
}

${ }^{1}$ Cambridge Centre for Environment, Energy and Natural Resource Governance (C-EENRG), University of Cambridge, 19 Silver Street, Cambridge CB3 1EP, United Kingdom

${ }^{2}$ Centre of Legal Sciences, Faculty of Law, Federal University of Santa Catarina, Campus Universitário Trindade, 88040-900, Florianópolis, Santa Catarina, Brazil

${ }^{3}$ Oxford Institute for Energy Studies, University of Oxford, 57 Woodstock Road, Oxford OX2 6FA, United Kingdom

${ }^{4}$ Department of Environmental Science, Radboud University, PO Box 9010, 6500 GL, Nijmegen, The Netherlands

${ }^{5}$ Department of Geography, University of Exeter, Rennes Drive, Exeter EX4 4RJ, United Kingdom

${ }^{6}$ Cambridge Econometrics Ltd, Covent Garden, Cambridge, CB1 2HT, United Kingdom

${ }^{7}$ Centre for Sustainable Development (GREENS) at the Universidade do Sul de Santa Catarina (UNISUL), 219 Trajano Street, 88010-010, Florianópolis, Santa Catarina, Brazil

${ }^{8}$ MIT Portugal Program - Sustainable Energy Systems, IST, at the University of Lisbon, Av. Rovisco Pais, 1, 1049-001 Lisbon, Portugal

Corresponding author email: map75@cam.ac.uk 


\section{Abstract (205 words)}

Hydroelectricity provides approximately $65 \%$ of Brazil's power generating capacity, making the country vulnerable to droughts, which are becoming increasingly frequent. Current energy law and policy responses to the problem rely on a sectorial approach and prioritise energy security and market regulation. Brazil has opted to increase energy security levels during periods of hydrological variability with national grid interconnection and thermal plants backup. Additionally, Brazil has created the Energy Reallocation Mechanism (MRE) to manage the generators' financial impacts in times of insufficient water. This policy, however, was unable to avoid the high financial exposure of generators in the spot market during the severe droughts experienced in the period 2013-2017. To explore how a more diversified electricity matrix can contribute to reducing hydrological risk, this article uses Integrated Assessment Modelling (IAM) techniques to analyse future macroeconomic and energy scenarios for Brazil in a global context, aligned with the Brazilian Nationally Determined Contributions (NDC) under the 2015 Paris Agreement on Climate Change. We show that the addition of non-hydro renewables is an advantage from the integrated Water-Energy-Food nexus perspective because it reduces tradeoffs amongst the water and energy sectors. Our conclusions suggest that a nexus perspective can provide useful insights on how to design energy laws and policies. 


\section{Keywords}

Hydropower - Hydrological risk - Electricity mix - Water-Energy-Food Nexus - Brazilian Law and Regulation - Integrated Assessment Modelling (IAM)

\section{Introduction}

The Brazilian power sector stands out for its low-carbon intensity, where renewable sources account for $81.8 \%$ in power generating capacity (MME, 2018). A closer look into the Brazilian electricity mix reveals that this is due to the predominance of hydroelectricity, which currently provides $63.9 \%$ of installed capacity (MME, 2018), whereas non-hydro renewable sources', such as wind, solar and biomass, only account for 17.2\% (MME, 2018).

Hydropower currently represents $1,096 \mathrm{GW}$ of the world's installed capacity, generating $16.6 \%$ of the world's electricity from all sources (REN21, 2017). Brazil is ranked as the second amongst the top countries in hydropower capacity, namely, China, the United States, Canada, Russia and India, which, in sum, account for about $62 \%$ of global installed capacity (REN21, 2017).

Recent episodes of droughts in the period 2012-2016, especially in the Southeast Region, have exposed Brazil's overreliance on water to produce energy. This article analyses the current energy law and policy responses to this problem. Water resources, even when considered from the perspective of energy law (Bradbrook, 1996; Heffron and Talus, 2016a), are important beyond their energy-generation uses. This is due to the fact that water is a 'natural resource' and, 
as such, its uses and cycles impact the environment and climate change, raising challenges of natural resources management and conservation. Additionally, water use is key for agricultural and industrial uses, as well as for residential (including urban) ones. Recent attempts to conceptualise energy law have highlighted the fact that 'energy law does not exist or evolve in a vacuum', which means interactions with other closely related areas of law, such as environmental and climate change, are features of energy law (Heffron and Talus, 2016b). Much like in international law, in domestic law, the expression energy law is best understood as all the laws that are directly and indirectly relevant for energy (Viñuales, 2019).

The following analysis of hydrological risk and energy matrix composition in Brazil unveils shortcomings in the patterns of energy law and policy development, revealing mismatches in the way water is simultaneously perceived as 'energy resource' and 'natural resource'. Specifically, the current law and policy approach is sectorial, prioritising energy security and market regulation without sufficiently taking into account environmental and climate change concerns.

The term hydrological risk describes the quantity of water (either lack or excess) affecting operation of a hydropower plant, with potential impacts. Hydrological risk can be considered from different points of view. Brazil has opted to increase energy security levels during hydrological variability across the country with national grid interconnection and thermal plants backup. Additionally, Brazil has created the Energy Reallocation Mechanism (MRE) to manage the generators' financial impacts in times of insufficient water. The MRE establishes a compulsory hedge for total production from all the interconnected grid hydropower plants during dry periods. This mechanism helps alleviate hydrological risk, but it is not enough to eliminate it, particularly in times of 'systemic risk' caused by severe droughts (Barroso et al., 2003; Blomfield and Plummer, 2014). For successive years during the recent water crisis, hydropower 
generators were forced to purchase energy at higher prices in the spot market to comply with their contractual obligations, creating a large financial deficit of billions of Brazilian reais. This situation is currently the subject-matter of pending lawsuits under Brazilian courts and attempts of policy adjustment within the MRE scope.

It should be noted that while this article makes use of this episode to demonstrate the importance of diversification in the Brazilian electricity mix, it does not provide a 'solution' for current policies addressing the financial aspects of hydrological risk, namely the MRE and its adjustment factor (known as GSF - Generation Scaling Factor). An underlying issue of adverse hydrology in Brazil lies on its overreliance in just one type of power generation source that is vulnerable to variations in climate and rainfall patterns (De Lucena et al., 2009; Prado et al., 2016). An alternative approach to dealing with the adverse hydrology in Brazil's electricity mix, particularly diversification from the insertion of non-hydro renewable sources, could relieve this overdependence in a sustainable manner and provide synergy amongst energy sources.

Within a broader perspective, hydrological risk and the need of diversification of the electricity mix are part of the Water-Energy-Food Nexus ('nexus approach') challenges faced by Brazil across the water, energy and agriculture sectors. Changes in water patterns causing water and energy scarcity are due to a range of factors such as water management failures, inefficiency of use, and consecutive years of reduced precipitation (Millington, 2018). Moreover, they are linked to developments at the global level, such as increased soybean demand from international markets, which contributes to large-scale deforestation and land-use change (Mercure et al., 2017). Ultimately, all interactions within nexus sectors and pressures on Brazilian natural resources affect hydroelectricity generation, hence the need for diversification. 
This article aims at estimating a more diverse and sustainable electricity mix so that risks related to overreliance in just one generation source are mitigated. In the second section, the article provides background information about the Brazilian electric power sector and the current electricity mix. Next, the third section presents the current MRE policy key constraints. The article then discusses the diversification of the Brazilian electricity mix in the fourth section, based in the Integrated Assessment Modelling (IAM) tool E3ME-FTT, which explores future macroeconomic and energy scenarios for Brazil in a global context. These energy mixes are aligned with the government's current plans and strategies, such as the "nationally determined contributions' (NDCs) under the 2015 Paris Agreement on Climate Change. ${ }^{1}$ To conclude, the modelling findings concerning the insertion of non-hydro renewables in the Brazilian electricity mix are framed into the policy challenges and the nexus approach, in pursuit of environmental and climate change interfaces integration into energy law and policy.

\section{Background}

\subsection{Hydroelectricity predominance and the electricity mix in Brazil}

Predominance of hydroelectricity in the Brazilian electricity mix reflects a historical option to benefit from the country's abundance in water resources. Holding approximately $20 \%$ of the world's water supply, Brazil uses hydropower electricity since the late $19^{\text {th }}$ century (Magalhães and Tomiyoshi, 2011a). Major investments in hydroelectricity expansion have started during the 1960's and 1970's, when large hydropower plants were built and became the backbone of the

\footnotetext{
${ }^{1}$ Adoption of the Paris Agreement, Decision 1/CP.21, 12 December 2015, FCCC/CP/2015/L.9, Annex.
} 
nation's electric generation (Magalhães and Tomiyoshi, 2011b). For instance, Itaipu, a Brazilian and Paraguay's enterprise that started operating in 1984, is the second largest hydropower plant in the world, with installed capacity of 14,000 MW, surpassed only by the Three Gorges Dam in China, with 22,500MW. Currently, the Brazilian hydroelectricity system features 291 dams (each of them with reservoirs larger than $3 \mathrm{~km}^{2}$ and at least 30MW of installed capacity), alongside small power stations and hydropower generators, corresponding to the total hydro installed capacity of 98,094MW (MME, 2018). The lowest energy generation costs in Brazil comes from hydropower plants (Corrêa da Silva et al., 2016).

Much of Brazil's hydroelectric potential lies in the Amazon River basin, which already has three large dams: Belo Monte (11,233MW) in the Xingu river basin, Jirau (3,300MW) and Santo Antonio (3,250MW), both in the Madeira river basin. Construction of hydropower plants in the Amazon requires large investments and efforts to connect the transmission grid from these remote areas to the consuming market, not to mention the environmental impacts in flooding large areas of rich biodiversity and often under indigenous occupation, and the social impacts in local population displacement (Inti Leal et al., 2017).

Thermoelectric plants, fuelled by natural gas, coal, oil, nuclear and biomass, play a complementary role in the Brazilian electricity mix to ensure energy security: whenever there is a reduction in water generation, the National System Operator (ONS) authorizes thermal plants to operate. This means they have increased their share in the electricity mix over the last years, to support periods of peak demand and drought (Luomi, 2014).

Since implementation of the Programme of Incentives for Alternative Electricity Sources (PROINFA, Law 10,438/2002) in 2004, non-hydro renewable sources are being incorporated to the Brazilian electricity mix. At first, a feed-in tariff scheme was developed, which later was 
replaced by auctions dedicated to alternative resources. The government has adopted further policies granting subsidies schemes for wind, solar, biomass and small hydro plants (up to 30 MW) projects, such as: (i) at least $50 \%$ discount on tariffs charged by the transmission and distribution systems (Resolution ANEEL 77/2004); and (ii) requirement that these sources are the only ones available for purchase by Special Consumers (from $500 \mathrm{~kW}$ to $3 \mathrm{MW}$ ) on the energy Free Trade Environment (ACL) (Law 9,427/1996). Alongside such measures, significant reduction in wind power's generation costs has contributed to its fast growth, particularly in the North-East and South regions, representing today $7.9 \%$ of the installed capacity, while biomass and solar account for, $9.2 \%$ and $0.3 \%$, respectively (MME, 2018).

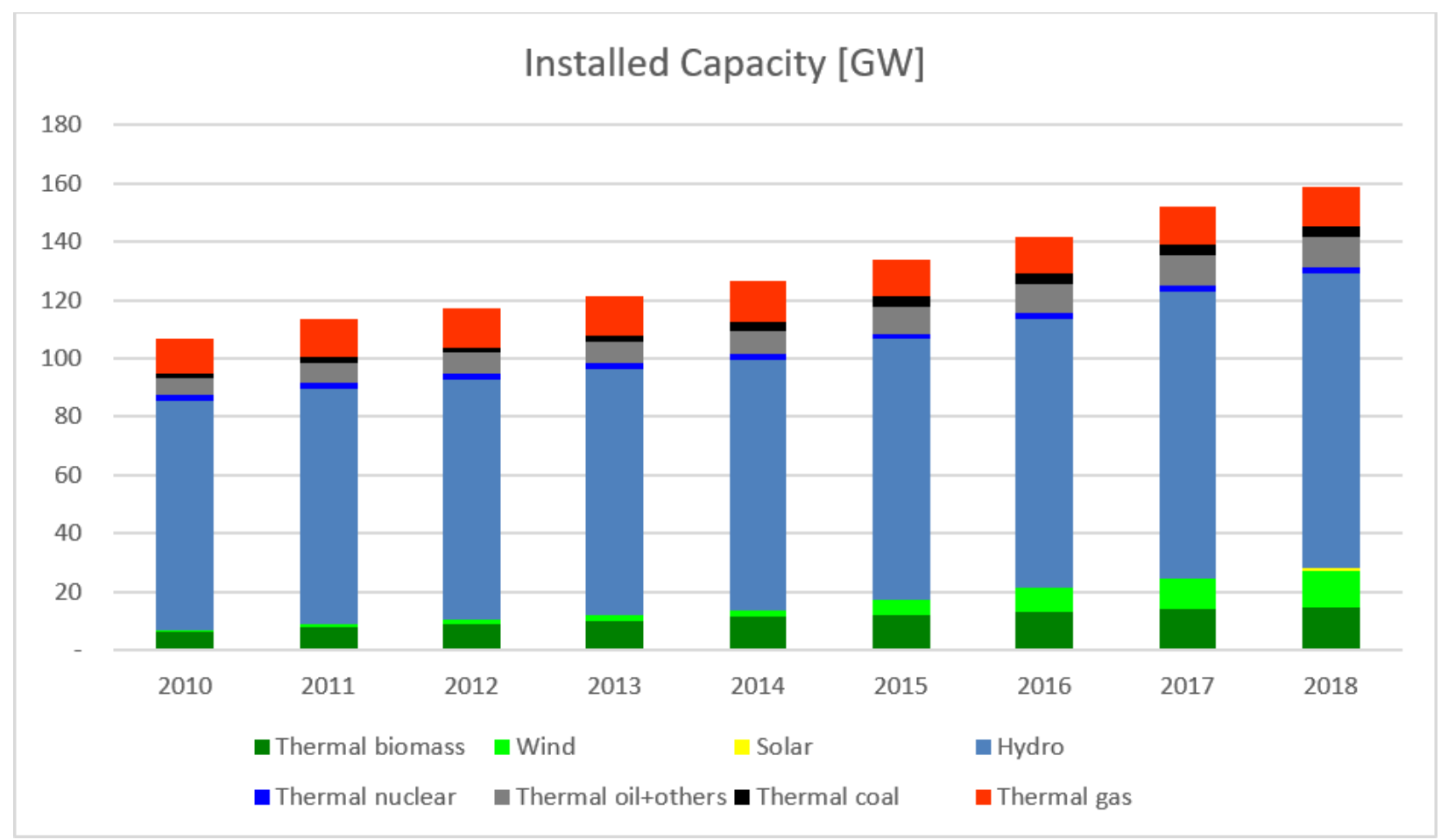

Figure 1: Installed capacity for Brazilian electricity generation between 2010 and 2018. Data from 'Boletim Mensal de Monitoramento do Sistema Elétrico Brasileiro', Brazilian Ministry of Mines and Energy (MME, 2018). 
The Ten-Year Energy Expansion Plan 2026 (PDE), elaborated by the Energy Research Company (EPE, 2017) for the Ministry of Mines and Energy (MME) forecasts a smaller reliance on hydropower and the intention to increase participation of non-hydro renewables, like wind, solar and biomass, to up to $48 \%$ of the electricity mix by 2026 .

The possibility to decrease hydro generation is aligned with the nexus perspective to achieve greater coordination of policies in the water, energy and agriculture sectors. Water scarcity is related to local and global environmental change, and the lack of coordination amongst policies of both the water and energy sectors can result in regulatory inconsistencies. For instance, electricity policy encouraging the use of water for power generation directly affects drinking water availability (Mercure et al., 2017).

The gradual reduction of the hydro share in the Brazilian electricity mix has already been noticed (Inti Leal et al., 2017). Besides PDE, recent studies point towards diversifying the Brazilian electricity mix in order to decrease its vulnerabilities and increase its resilience (Ruffato-Ferreira et al., 2017). For instance, some models emphasize how wind and solar sources, balanced by daily storage, can reduce the need to use thermal generation as backup capacity for the current system of hydropower reservoirs (Schmidt et al., 2016). Others suggest that hydroelectricity's role remain important in Brazil under stringent climate policy scenarios, as long as there is also an expansion of generation capacity of non-hydro renewables such as wind, solar and particularly biomass (De Lucena et al., 2016).

\subsection{Brazilian power sector relevant framework}


Since the 1930's Brazil has established a solid power sector regulation, starting with the 1934 Water Code as a trademark of state intervention in the electricity sector with the creation of government owned power companies (Magalhães and Tomiyoshi, 2011a).

In the 1990's, the Brazilian electricity sector's regulatory framework went through major modifications as one of the key targets in a vast reform process led by the Federal Administration (Oliveira, 2003). These reforms were predicated on a general concern with state bureaucracy, public management and public decision-making processes, and its structure's costs and efficiency. Furthermore, such concerns were thoroughly assessed by studies led by the then Ministry of Federal Administration and State Reform, which resulted in a robust document regarded as a general guideline for reforms - the Plano Diretor da Reforma do Aparelho do Estado (the State Reform Plan, 1995).

For the energy sector, the primary goal was to 'deverticalize' its structure, thus introducing competition in the power generation market and in some areas in the commercialization sector. In this new system, transmission and distribution were to remain as natural monopolies. In order to better regulate this hybrid market, the sector's regulatory institutions at the Federal level were redesigned. Administrative bodies, such as the National Electricity Agency (ANEEL, Law 9,427/1996), were thus created. During the early 2000's, the first set of reforms was revised, triggered by the 2001 power rationing crisis (Tolmasquim, 2012). The resulting regulatory framework, commonly referred to as the 'New Model', was enacted by Laws 10,847 and 10,848, both from 2004.

Since its creation in 1998 (Law 9,648), the National Grid Operator (ONS) is responsible for unifying the previously fragmented dispatch system, coordinating and monitoring the electric power generation and transmission facilities connected to Brazil's national grid, the National 
Interconnected System (SIN), that runs across the entire country. Currently, the vast majority of large-scale generators $(99,9 \%)$ are interconnected by SIN, with minimal Isolated Systems (ONS, 2018). ONS operates the centralized electricity dispatch system, considering each plant's energy generation availability. The decision about which plant to dispatch is based on the lowest possible cost to generate electricity restricted to hydrological affluence, water reservoir levels, thermal generation prices and operational restrictions (ONS, 2008).

The creation of the Electric Energy Commercialization Chamber (CCEE) in 2004 (Federal Law 10,848) has shaped a new wholesale energy market. CCEE is responsible for managing energy auctions in close articulation with the MME and ANEEL, as well as managing contracts in two separate markets: (i) the Regulated Trading Environment (ACR), in which contract rates are fixed by ANEEL, and which consists of 'captive consumers' (whose monthly energy consumption is under $500 \mathrm{~kW}$ ), who must purchase energy from local distribution companies; and (ii) the Free Trade Environment (ACL), in which energy prices and supply conditions are freely negotiated, and which consists of 'free consumers' (monthly consumption over $3 \mathrm{MW}$ ) or 'special consumers' (whose demand varies between $3 \mathrm{MW}$ and $500 \mathrm{~kW}$ ).

\section{Hydrological risk under the Brazilian perspective}

\subsection{Brazilian relevant law and regulation on hydrological risk}

Within a broad assumption, hydrological risks refer to issues related to the quantity and quality of the water, either too much or too little, affecting operation of a hydropower plant or other phases of the project (Blomfield and Plummer, 2014). More specifically, during operation 
of a hydropower plant, there is a risk of having insufficient water to support expected levels of electricity generation, with potential physical, financial, environmental and social impacts (Blomfield and Plummer, 2014).

Hydrological risk can be considered from different points of view. Firstly, to deal with the energy security threats of reduced reservoir inflows, Brazil's grid interconnection and energy portfolio comprising thermal plants backup are able to unravel seasonal hydrology variability across the country. Additionally, Brazil has designed its own regulation for allocation of hydrological risks amongst generators, the MRE, for a better management of water reservoir levels and to avoid high financial exposure of generators in the spot market.

The MRE is a compulsory hedge for total production of all hydropower plants, protecting generators as a group, irrespectively of individual production. It is based on observations, and although energy production of individual plants is significantly variable, total production of all hydropower plants together tends to be far more stable (Barroso et al., 2003). The reason for this is that Brazil has continental proportions, with regional disparities in rain patterns, and irregular energy production amongst generation plants throughout the year. In addition, reservoirs organised in cascade contribute to create greater dependence among generation facilities, which are typically built in interconnected watercourses, in a sequenced manner.

The MRE scheme consists of assigning credits that consider, on the one hand, the proportion between the sum of all energy produced within the MRE and, on the other hand, each participant's assured certificates of physical guarantee based on the plant's installed capacity. This calculation of the MRE adjustment factor is known as the Generation Scaling Factor (GSF). In case overall production is higher than the amount of overall assured certificates, hydropower generators will be reassigned a credit that covers their assured energy. Conversely, if hydro 
production of the group is below the total assured individual certificate, the generators will need to purchase extra energy in the spot market to cover the amount of energy sold in bilateral contracts (Barroso et al., 2003).

For instance, presume a situation in which the system is formed by 10 different generators, and each of them is allowed to sell 10 units of electricity (typically through bilateral contracts set in advance). In a first scenario, if 9 agents produce more than 10 units, and 1 agent produces 6 units (i.e. because of regional draughts) in a certain month, instead of purchasing the difference in the spot market to meet its contracted obligations, the 'underperforming' agent is allowed to purchase directly from its peers in MRE, because overall production in a given month exceeded expected production. In a second scenario, suppose all 10 agents produce less than 10 units each. This means it is not possible for hydropower generators to collectively meet their contracted obligations through MRE and its compensation system. In this case, they will be forced to purchase the difference in the spot market (from thermal sources, usually), since overall production is collectively below expected and contracted levels.

In hydro-based systems, however, spot prices are higher in drought situations, precisely when hydro plants have lower production capacity and need to purchase energy to meet their contracted demand (Barroso et al., 2003). This is exactly what happened in 2012-2016, when severe droughts affected reservoir levels of hydropower plants in all regions of the country, particularly in the Southeast Region - Brazil's industrial core. Consequently, the GSF levels plunged, creating huge deficits in hydropower generators' revenues. According to Maia, 2017, only in 2017 , the deficit accounted for approximately $\mathrm{R} \$ 39.7$ billion. Up until now, the debt is subject to controversy, and the Brazilian government is currently drafting new reforms in the wholesale market specifically to solve this financial imbalance. 
Pursuant to Law 13,203/2015, it is possible to renegotiate debts which resulted from MRE's usage during the droughts' period, upon certain conditions established by ANEEL's Normative Resolution 684/2015. The edition of Law 13,203/2015 was preceded by public consultations, with participation of agents affected by the hydrological risk policy.

Moreover, this law updated the MRE so that it now enables generators to transfer the financial impacts of hydrological risks to consumers (and potentially deter lawsuits against debts). Accordingly, in the ACR, 'hydrological risk renegotiation shall occur through the transfer of hydrological risk to consumers via insurance premium payment by the generator' (Article 4). Renegotiation is limited, however: although most consumers met pre-established requirements (within ACR), hydro generators have not renegotiated past ACL contracts and related debts, which are the subject-matter of pending legal disputes.

On the other hand, in the ACL, a different issue arises. Normative Resolution 684/2015 provides that 'hydrological risk renegotiation in the ACL shall occur through an insurance premium payment, equivalent to the rights and obligations bound to the existing reserve energy capacity, as established by Article 3-A of Law 10,848/2004' (Article 7). In other words, instead of risks, hedge for assured energy is transferred. Since generators were hesitant about this solution, further litigation has followed (Polito and Maia, 2017).

\subsection{Recent developments: lawsuits and responsive regulation}

Before enactment of Law 13,203/2015 and Resolution 684/2015, many hydropower generators had filed lawsuits against the Federal Government and ANEEL to avoid paying GSF debts. Initially, the Judiciary Power granted provisional measures in favour of the generators. As 
a result, normal operation of the energy market remained impaired for a while. Law 13,203/2015 has deliberately required that only generators who waive their rights to plead in court the suspension of GSF related payments would be eligible to renegotiation (Article 1, para. 10).

Meanwhile, several hydropower generators in the ACL have filed lawsuits to question whether the GSF mechanism is legal or not under severe droughts and its financial impacts. It is argued that the original economic conditions upon which the concession contracts were agreed have become unbalanced, inasmuch as the use of the GSF mechanism arbitrarily imposed financial losses beyond reasonable and proportional expectations.

Most of the lawsuits are still pending, and the provisional measures to suspend immediate GSF related payments have been revoked to favour the Federal Government's position².

\section{An alternative approach to dealing with hydrological risk in Brazil's electricity mix}

Although it can be recognised that the MRE is not particularly well designed to cover the 'systemic risk' caused by serious droughts, in which there is unavailability of water in the reservoirs to produce hydroelectricity and generators are exposed to high energy prices in the spot market, revision of the current policy or proposal of new mechanisms to deal with financial risks in a new reality is outside the scope of this article. Precisely, this article argues that current short-term solutions to address this problem overlook structural issues related to hydropower generation and the need for long-term solutions.

\footnotetext{
2 The landmark lawsuits involve two of the major generators' associations, ABRAGEL - Associação Brasileira de Energia Limpa (Supreme Court, Reclamação N. 24.781/DF) and APINE - Associação Brasileira dos Produtores Independentes de Energia Elétrica (Federal District Circuit, Case N. 34944-23.2015.4.013400). Results of the provisional measures as of November 2018; decisions still subject to appeal.
} 
The underlying challenge of overdependence in one type of power generation source that is vulnerable, especially under the foreseeable scenarios of climate variability and change, should become central to the hydrology adversity discussion. Otherwise, if and when more droughts come in the recent future, not only more financial deficits will follow, but also other issues may arise, such as more environmental pressures due to thermal backup dispatch, competition amongst water uses, and deforestation influences in hydrology (as discussed in item 5. below). Changes in the electricity mix, in particular the insertion of non-hydro renewable sources, could maintain energy security in a sustainable manner, with greater synergy amongst energy sources. This mutually pressuring relationship, between climate change impacts on water availability and alternatives to hydro-based power generation, cannot be regarded as irrelevant.

Therefore, given all the aforementioned benefits, power generation diversification in Brazil is presented in this section through development of the Integrated Assessment Model (IAM) E3ME-FTT. A description of the modelling platform can be found in the Supplementary Information. $^{3}$

\subsection{Power sector scenarios and the Brazilian NDC}

In the context of the Paris Agreement, Brazil committed to reduce greenhouse gas emissions by $37 \%$ below 2005 levels in 2025, and by 43\% below 2005 levels in 2030. In the power sector, this commitment means to increase the share of renewables (other than hydropower) in the power supply to at least $23 \%$ by 2030, including by raising the share of wind, biomass and solar (Brasil, 2015). By January 2018, the added power capacity of biomass, wind and solar reached 17.8\% (see Figure 1, above).

\footnotetext{
${ }^{3}$ More detail about the model and its applications can be found in (Mercure et al., 2018).
} 
Using E3ME-FTT, a bundle of power sector policies for Brazil are grouped in eight scenarios presented in Table 1 . The analysis focuses on the potential impacts of implementing policies fostering the uptake of wind, solar and biomass-based electricity, as well as policies to limit the use of fossil fuels, consistent with the Brazilian NDC. Moreover, the study includes the implications of limiting hydropower and bioenergy in the electricity generation mix, based on environmental and energy security considerations. Table 1 presents a summary of the eight scenarios, with a description of how policy instruments were used on each of them, and what were the effects in the Brazilian electricity mix. ${ }^{4}$ It starts with historical trends in the Brazilian power sector (captured by the Baseline scenario, as explained below), and then it simulates single policy instruments, to study their effect in the Brazilian power generation capacity mix. The resulting power matrix in 2030 for each scenario is presented in Figure 2.

The Baseline scenario relies on historical data (1970-2018) to capture technology diffusion trends, globally as well as in Brazil. The rate of technology diffusion in the model is influenced by its own history (path dependency). This reflects the inertia of the system, and the fact that diffusion builds momentum as it progresses: the faster the diffusion of an innovation is, the faster it can become (Mercure et al., 2018). Using the historical data, in combination with its complex representation of technology diffusion, E3ME-FTT is able to project current technological trajectories. Naturally, these projections are influenced by the assumptions behind each scenario, as well as the inherent modelling approach of E3ME-FTT. ${ }^{5}$

The Baseline scenario assumes no new climate policies for Brazil, as well as no new carbon policies for the rest of the world. Therefore, the diffusion of low carbon technologies in this

\footnotetext{
${ }^{4}$ A more detailed description of the underlying policy instruments used in these scenarios can be found in Table S1 of the Supplementary Information.

${ }^{5}$ A detailed discussion on the main inputs used by E3ME-FTT is included in the Supplementary Information, section 'Inputs and scenario analysis'. A comparison between the trends described in the Baseline scenario and the official projections from the Brazilian Ministry of Mines and Energy is part of the Supplementary Information section 'The difference between E3ME-FTT and other models' and 'Comparison of the E3ME-FTT Baseline Scenario with the projections from MME and EPE'.
} 
scenario can be considered a conservative estimation. Based on the policy instruments described in Table 1, the potential effects of different policies in the Brazilian power matrix can be analysed (the resulting power matrix for each scenario by 2030 is presented in Figure 2). ${ }^{6}$

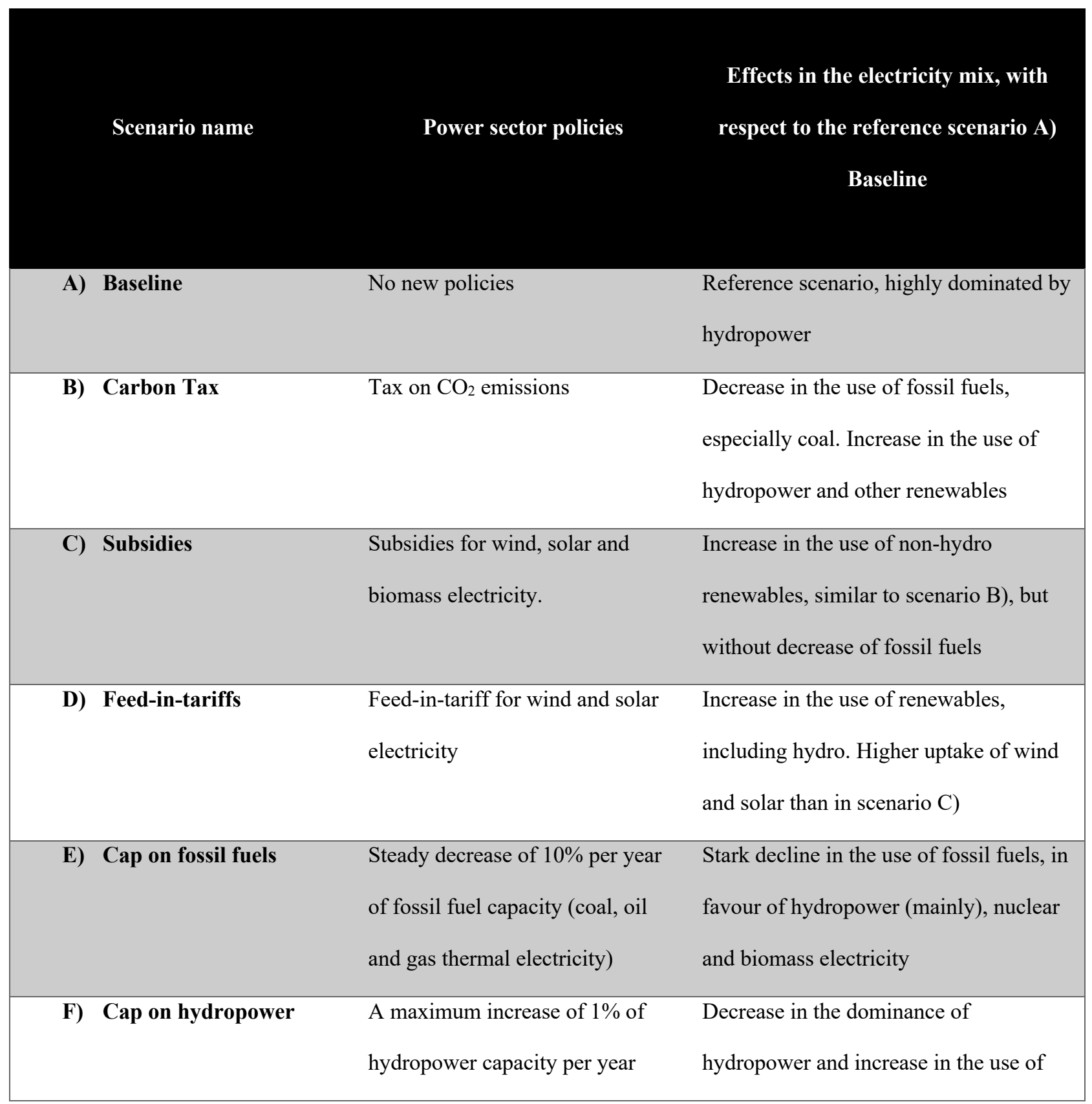

\footnotetext{
${ }^{6}$ A comparison of these results with the official projections from the Brazilian Government, available in the Ten-Year Energy Plan 2026 can be found in the Supplementary Information, section 'Comparison of the E3ME-FTT Baseline Scenario with the projections from MME and EPE'.
} 


\begin{tabular}{|c|c|c|}
\hline & & fossil fuels and non-hydro renewables. \\
\hline G) Mix & All the previous policies together. & $\begin{array}{l}\text { Stark decline in the use of fossil fuels, } \\
\text { replaced mostly by biomass and wind, } \\
\text { and in a minor degree by solar. Hydro } \\
\text { still dominant, but on a lower degree. }\end{array}$ \\
\hline H) Mix + cap on biomass & $\begin{array}{l}\text { All the previous policies together, } \\
\text { in addition to a limit of } 2 \% \\
\text { increase on biomass power } \\
\text { capacity per year. }\end{array}$ & $\begin{array}{l}\text { Stark decline in the use of fossil fuels, } \\
\text { replaced mostly by wind. Biomass and } \\
\text { solar also increase their participation. } \\
\text { Hydro still dominant, but on a lower } \\
\text { degree. }\end{array}$ \\
\hline
\end{tabular}

Table 1: Summary of eight scenarios analysed in this article, using the Integrated Assessment Model E3ME-FTT. 

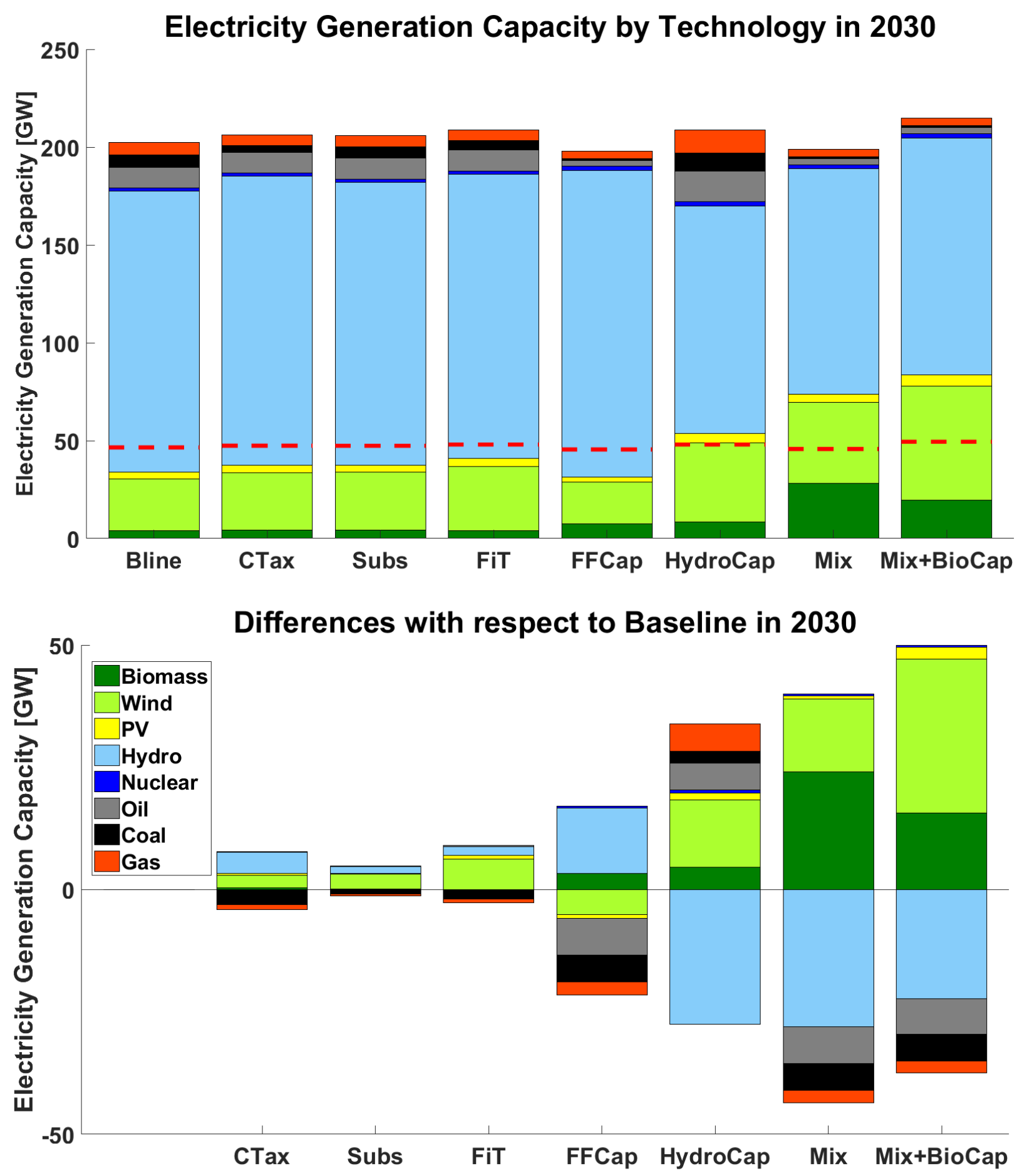

Figure 2. Top: Electricity generation capacity by technology in 2030, for each of eight scenarios presented in Table 1 . The red dotted line represents the Brazilian NDC target of $23 \%$ power supply share of non-hydro renewables by 2030 . Only scenarios 'Hydro Cap', 'Mix', and 'Mix + Bio Cap' were able to reach that target. Bottom: Differences in power generation capacity between each scenario and the Baseline by 2030. 
The $23 \%$ target of non-hydro renewable electricity by 2030 stated in the Brazilian NDC has a double objective: limit hydrological risk and foster deployment of renewables. In other words, it tackles two out of three nodes of the energy trilemma: energy security and sustainability (World Energy Council and Wyman, 2010). In all the scenarios presented in Figure 2, only the last three have non-hydro renewable levels consistent with the NDC's target (Hydro Cap, Mix and Mix + Bio Cap). These three scenarios have one thing in common: they put a cap on maximum capacity of hydroelectricity in the system. Scenarios with policies supporting deployment of wind, solar and biomass, but without imposing any obligation on hydroelectricity (such as Scenarios Subs and FiT), have an increase in non-hydro renewable contribution with respect to Baseline, but they do not reach the NDC's target. In the case of scenarios that impose a burden on fossil fuel generators, either in the form of a tax (scenario Carbon Tax) or in the form of a cap in capacity (scenario FF Cap), the market share lost by fossil fuels is taken mostly by hydropower generators. These scenarios suggest that the dominant position of hydropower in the Brazilian power sector cannot be challenged only by a single policy mechanism, either supporting other renewable technologies or by putting a burden on fossil fuel generators. A limitation on hydropower generation must also be implemented.

Building resilience against hydrological risks is not the only challenge faced by the Brazilian power sector. In alignment with its NDC, Brazil has to reduce its greenhouse gas emissions by $43 \%$ below 2005 levels in 2030 . Figure 3 presents the power sector emission trajectories of the eight scenarios introduced above, from 2018 until 2030. As a reference, the red dotted lines correspond to $43 \%$ of power sector emissions in 2005 (43\% of $9.7 \mathrm{MtC})$. 


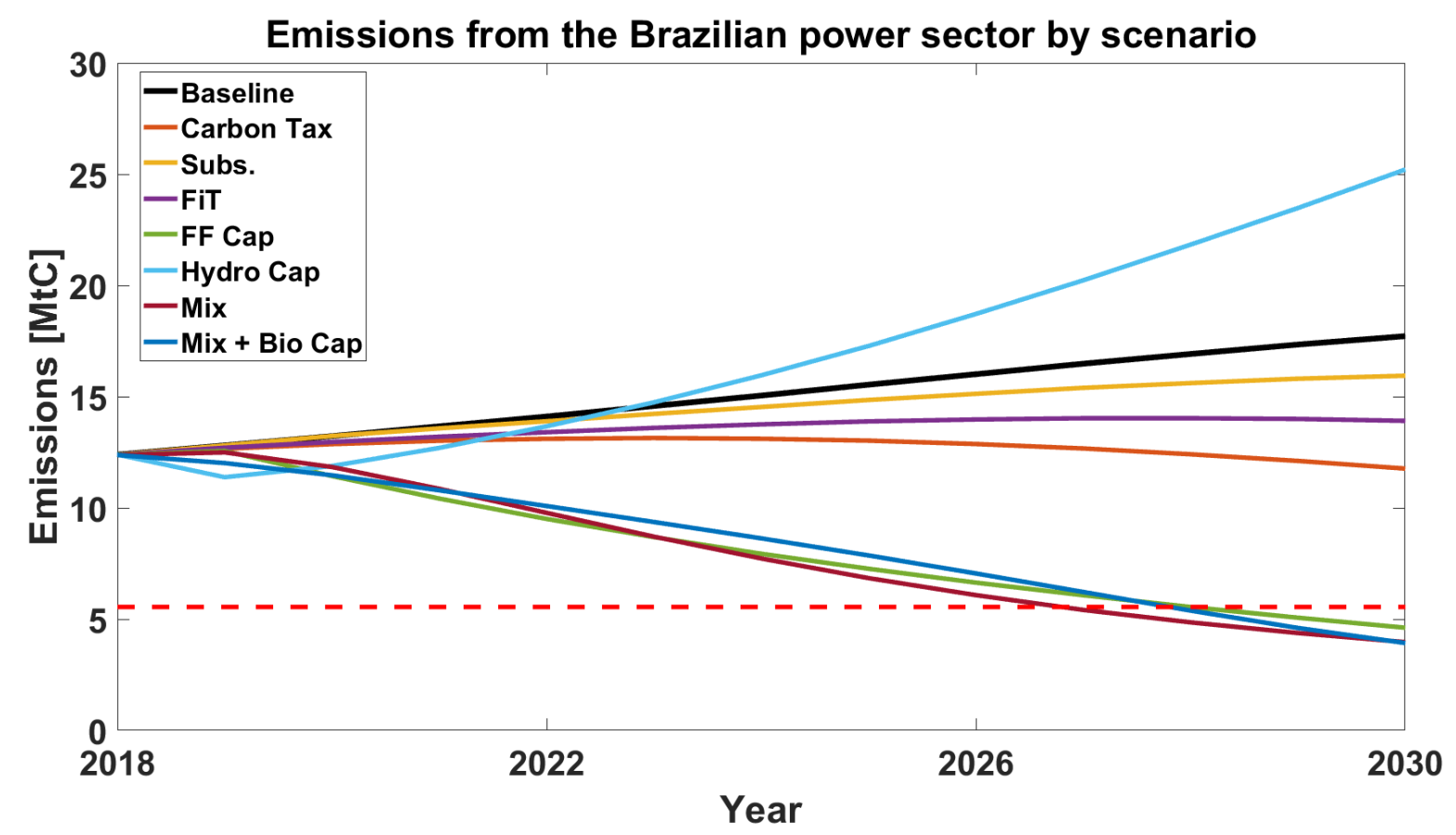

Figure 3: Power sector emissions by scenario. The horizontal red dotted line corresponds to a reduction of $43 \%$ of power sector emissions in 2005.

In Figure 3, only three trajectories reach abatement levels close to the $43 \%$ of 2005 reference levels by 2030: the scenarios FF Cap, Mix and Mix + Bio cap. All other scenarios are closer to Baseline in terms of emissions, and the scenario Hydro Cap has even higher emission levels. The counterintuitive behaviour of the Hydro Cap emissions trajectory can be explained looking at the bottom chart of Figure 2: hydropower is replaced in that scenario by other renewables (green and yellow areas representing wind and solar, respectively), but also by fossil fuels (grey, black and orange bars, representing oil, coal and gas, respectively). Therefore, in net terms, that scenario generates net positive emissions by partly replacing hydropower with fossil fuel technologies.

Addressing the energy trilemma requires to balance energy security and sustainability with a third component: affordability. Figure 4 shows the economic impact of the different scenarios, with respect to the baseline, on electricity prices, as seen by the consumer, ceteris-paribus. 


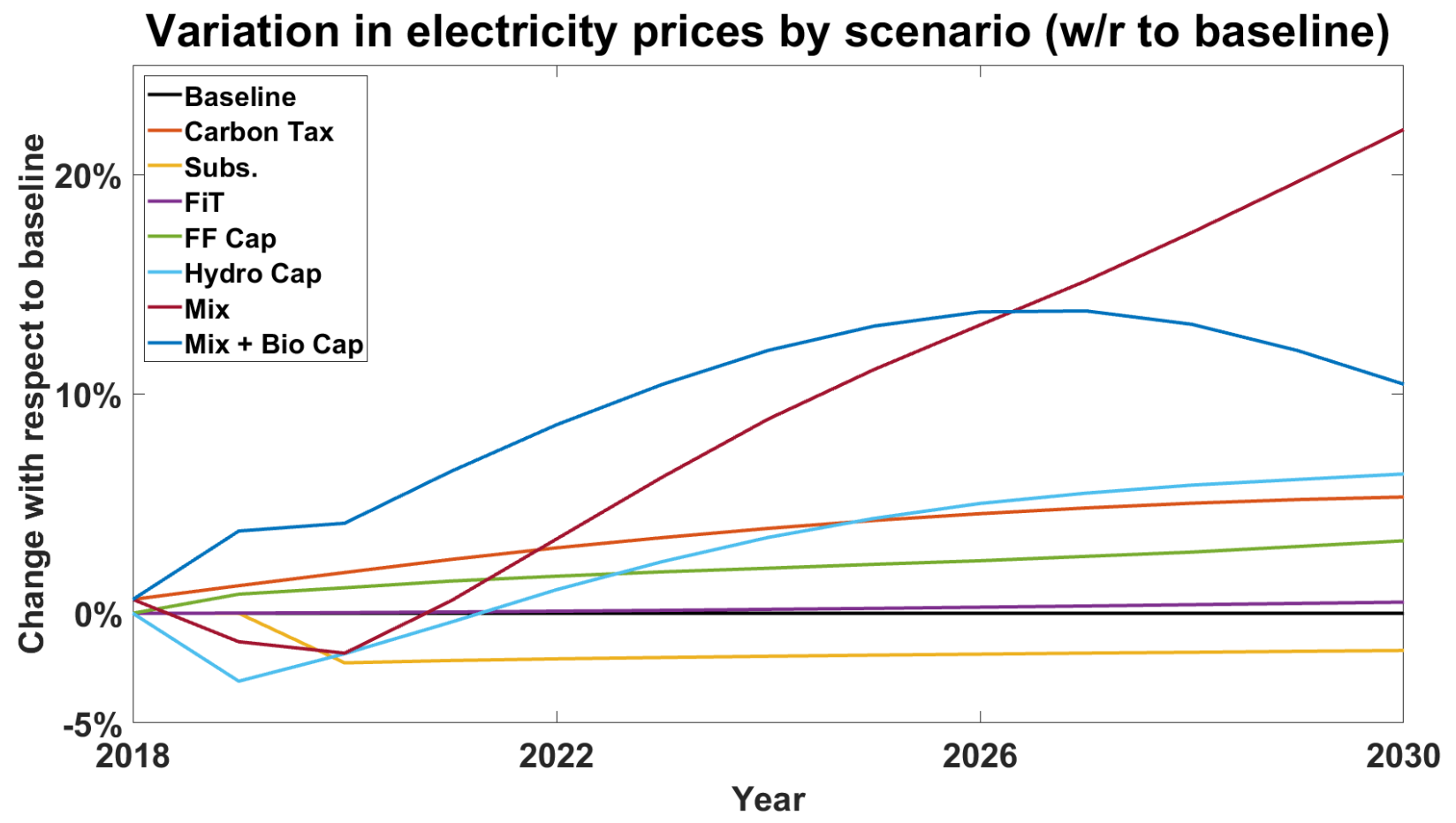

Figure 4: Variation in electricity prices with respect to baseline, by scenario, in percentage terms. Negative percentages mean a decrease in the price of electricity (scenario Subs).

As shown by Figure 4, the three scenarios with a larger increase in the price of electricity in the long term are those that impose a cap on hydroelectricity: Hydro Cap, Mix and Mix + Bio Cap. This is an expected behaviour, given the competitiveness of hydroelectricity in Brazil. The increase in the price of electricity in scenario Mix is particularly significant, mostly driven by the replacement of hydroelectricity and fossil fuels by biomass and wind (see the bottom chart of

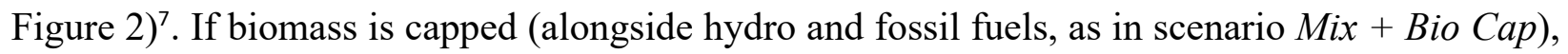
the price of electricity is expected to rise in the short term due to the fast uptake of wind (the blue curve is the highest on early 2020s in Figure 4). However, the impact on the price of electricity

\footnotetext{
${ }^{7}$ The increase in the price of electricity in the scenario Mix is reversed after 2030, a behaviour that cannot be seen in Figure 4. In essence, the same behaviour observed on scenario Mix + Bio Cap (a peak in 2027) is observed in scenario Mix, but after 2030. The reason is the same: steady deployment of wind energy drives the price of wind power down. In scenario Mix + Bio Cap, this behaviour is accelerated by capping biomass, a competitor of wind power.
} 
is expected to decrease over time, due to learning effects: wind power becomes cheaper with large scale of deployment (Rubin et al., 2015).

E3ME-FTT features learning curves and fully endogenous power system stability constraints that facilitate the modelling of learning effects, path dependency and other complex phenomena (Mercure et al., 2018). ${ }^{8}$

\section{Discussion}

Brazil's centenary hydroelectricity experience, as the predominant source in its electricity mix, is substantiated in the 'culture of abundance', considering historical hydrological records. Large reservoirs provide energy security in dry seasons and in times of drought (de Souza Dias et al., 2018). When full, these reservoirs can keep generating for some months in cases of changes of rainfall patterns, thus reducing their vulnerability (Ruffato-Ferreira et al., 2017).

Hydropower generation is characterized as a renewable source of energy as the plant is fuelled by water, which is constantly refilled by nature. While this characterization is adequate, considering the constant movement of the water cycle, various factors can affect water availability. Not only water is unevenly distributed in the world, but also pollutants, withdrawal of underground or surface water faster than its replenishment, population growth, and changes in precipitation patterns can all influence water availability (Miller and Spoolman, 2012).

As mentioned, the unexpected and severe droughts in the 2012-2016 period has stimulated reflection about the protagonism of hydropower in Brazil, initially focusing on the effects of

\footnotetext{
${ }^{8}$ A better understanding of the underlying dynamic behind the results presented above can be achieved by assessing the Supplementary Information, where a more detailed description of E3ME-FTT is presented, and the scenarios are compared with the Ten-Year Energy Expansion Plan from the Brazilian Government.
} 
interruption of hydropower generation in the generators' revenues, seen as the most urgent issue in the sector at the moment. Nevertheless, the discussion about hydrological risk is inserted in a much broader prospect on the composition of the Brazilian electricity mix as a whole.

First of all, hydrological risk has triggered frequent thermoelectrical dispatch, originally designed as backup for exceptional circumstances in hydropower generation. Thermal fuels used in Brazil are: gas, biomass, oil, coal and nuclear (Figure 1). Except biomass (the subject-matter of a later discussion), all the aforementioned thermal fuels can raise environmental concerns: oil, gas and coal are non-renewable fossil-fuels (Santos and Rodrigues, 1998) and nuclear expansion brings challenges, such as nuclear waste management (Srinivasan and Gopi Rethinaraj, 2013).

As already recognized by PDE and the Brazilian NDC, diversification is inevitable in the composition of the future Brazilian electricity mix, emphasizing that non-hydro renewable sources should be encouraged, such as wind, solar and biomass. As these sources increase their participation in the matrix, the legal framework as it exists today needs to be adjusted.

Although all renewable energy strongly depends on climate conditions, non-hydro renewables are not related to water availability. That is why increasing participation of non-hydro renewables in the nation's power generation mitigates the risks of frequent water scarcity periods. In other words, diversification of the electricity mix will strengthen Brazil's resilience to prolonged scarcity of specific resources, particularly water in the context of climate change. A well-designed diversification plan for the power sector requires balancing the three aspects of the energy trilemma: energy security, sustainability and affordability.

The advantages of increasing generation of wind and solar is that they can complement hydroelectricity generation in dry seasons. As a matter of fact, periods of low rainfalls coincide with higher wind speed during winter and spring in the Northeast and Southeast Regions (Corrêa 
da Silva et al., 2016) and solar irradiation in the whole country is high ${ }^{9}$ compared to other countries' averages (INPE, 2006). Both sources present high potential to increase their capacity in the mix, although wind participation has grown since 2009, with the introduction of wind power auctions. The regulatory framework has been supportive of investments in renewable energy, which has facilitated competitive prices for wind power.

Biomass energy has a strategic role in Brazil as sugarcane harvest coincides with the drought period in the Southeast / Center-West region, where many important hydroelectric power plants are located. This way, biomass thermal power plants contribute for system security when reservoirs' capacity is low (ANEEL, 2008). ${ }^{10}$ Moreover, many climate change policy scenarios assume biomass will play a significant role in the decarbonisation of the global economy (Jonker et al., 2015; Rose et al., 2014). In the case of biomass power in Brazil, production is based on sugarcane bagasse, resulting from ethanol production. Consequently, the association of electricity generation and production of liquid biofuels raises some critical issues such as: (i) the risk of decreasing ethanol production due to the introduction of electric vehicles; (ii) potential impacts on land use and traditional agriculture (De Lucena et al., 2016).

Some of the policy portfolios and scenarios discussed in this article include a potentially significant increase in the use of specific natural resources. For instance, the scenarios Mix, Mix+BioCap and FFCap present a significant increase in the use of biomass, wind and hydropower, respectively. For the aforementioned scenarios to be plausible and relevant, the demand for primary energy resources, such as primary biomass, needs to be accounted for. Moreover, the changes in the availability (and therefore cost) of energy resources may have

\footnotetext{
${ }^{9}$ Brazil is inside an inter-tropical region and captures solar energy during the entire year. According to the Brazilian Atlas of Solar Energy, the daily solar radiation in Brazil is between $4.500 \mathrm{Wh} / \mathrm{m}^{2}$ to $6.300 \mathrm{Wh} / \mathrm{m}^{2}$.

${ }^{10}$ Regarding intermittency, although its annual production varies, biomass is not considered an intermittent power source in the same sense as solar and wind because its production is much more predictable throughout the year. Biomass is more in line with hydropower, which production also varies, according to raining seasons.
} 
impacts of different magnitude on the different types of power plants. Consequently, investment decisions have to consider these heterogeneous impacts when searching for efficient investment portfolios. Our modelling platform takes all of these issues into consideration, using a model of natural resources use and depletion based on cost-supply curves and LCOE cost distributions (Mercure and Salas, 2013, 2012). The Supplementary Information presents a description of the treatment of natural energy resources and cost distributions in E3ME-FTT, discusses its influence in the results presented here, and compares these results to the official projections from the MME (EPE, 2017).

From a multisectoral perspective, hydrological risk exposes a trade-off between the energy and water sectors, inasmuch as the electricity policy encouraging the use of water for generation of energy in a scenario of intense droughts affects other uses of water (Mercure et al., 2017). Similarly, a trade-off between the food and water sectors can be identified. Under future climate change, some regions of high agricultural productivity in Brazil will likely experience increased frequency of droughts, which can limit Brazil's capability to meet growing demand for agricultural commodities, such as soybeans exported to China (Lambin and Meyfroidt, 2011). Expansion of agricultural production to meet future demand, combined with geographical migration of land use along patterns of shifting climate, will exert additional pressure on the system through deforestation, water shortages and tension between competing uses of water (Marengo et al., 2011). Since the challenges of water scarcity, energy crisis and large-scale landuse are all interrelated, the nexus approach can provide integrative policy solutions for the natural resources involved in the three sectors of water, energy and agriculture.

In fact, there is evidence that deforestation of the Amazon disrupts the positive feedback loop of this Biome acting as an attractor of huge amount of moisture from the Atlantic, the so-called 
'flying rivers' phenomenon (Nazareno and Laurance, 2015), as Brazilian authorities have recently acknowledged. ${ }^{11}$ In addition, the complex interplay of socio-economic pressures leading to changes in weather patterns, and thus water resource scarcity, exemplifies the dire need for a nexus approach in integrative policymaking in Brazil (Zemp et al., 2017).

\section{Conclusion and policy implications}

The study of hydrological risk and energy matrix diversification in Brazil indicates low level of interactions between energy and environmental and climate change law and policies. For instance, the use of fossil-fuel sources as back-up power generation and its impacts on the environment and climate change are not adequately discussed in the country, as well as the development of a robust non-hydro renewable sources framework, and the implications of sharing natural resources amongst the sectors of energy, water and food. Moreover, although PDE considers the Brazilian NDC on its formulation, hydropower as a baseload power source and natural gas thermal generation still feature prominently in the plan.

While focusing on the management of water as 'energy resource' (Bradbrook, 1996; Heffron and Talus, 2016a) energy law must seek to ameliorate the impacts of the hydro-energy activities on the environment, and particularly the management and conservation of water as 'natural resource'. Integrative policies, as suggested, are opportunities to apply at least three of what Heffron et al. (2018) termed the 'Energy Law's Seven Principles'. The design of policies to diversify the matrix, thus ensuring the continuous availability of energy supply to achieve sustainability and mitigation of future situations of hydrological risk such as those lived at the

\footnotetext{
${ }^{11}$ In November 2017, The Guardian published an article entitled 'The Amazon effect: how deforestation is starving São Paulo of water' in which Jerson Kelman, president of São Paulo water company SABESP, and João Doria, the mayor of São Paulo, both argued that deforestation in the Amazon is a risk for the water supply in central and Southeast Brazil. In their opinion, without the forest humidity there is no movement of water in the atmosphere to preserve the cycle of rain (Watts, 2017).
} 
present, refers to the 'energy security and reliability principle' (Heffron et al., 2018). Furthermore, policies that take into account the side effects and synergies in the governance of the natural resources involved in the water, energy and agriculture sectors under the nexus perspective and climate-change strategies are aligned both with the 'principle of prudent, rational, and sustainable use of natural resources', and the 'principle of the protection of the environment, human health and combating climate change'12.

For such, it is necessary to reduce the level of fragmentation in policy making among the correlated water, food and energy sectors. In this context, the nexus approach can contribute to identify the complex interactions amongst those sectors, considering the scientific analysis and the political, economic and legal constraints both in Brazil and worldwide (Mercure et al., 2017). Under the nexus approach adopted by this work, we have identified that the environmental challenges of changes in water pattern are linked to the socio-economic challenges of energy security, overreliance in hydroelectricity, and hydrological risks. In order to assess scenarios with lower hydroelectricity dependence, this analysis was followed by the integration of the scientific-insight into the policy perspective, throughout the Integrated Assessment Modelling (IAM) tool E3ME-FTT. This model has presented alternatives to the policy challenges of reducing reliance on water resources and including non-hydro renewables in the Brazilian electricity mix.

Particularly for the purpose of mitigating hydrological risks, apart from the current MRE policy focused on security, market regulation and financial aspects, this new perspective gives adequate weight to the environmental and natural resources involved in the process of energy generation from water. Nevertheless, further similar analysis of each of non-hydro renewables'

\footnotetext{
12 Besides the mentioned principles, the 'Seven Principles of Energy Law' include the following ones: sovereignty over onshore and offshore energy resources, access to modern energy services, energy justice, and resilience (Heffron et al., 2018).
} 
share in the electricity mix and their impacts in deforestation, land-use change, energy scarcity, and vulnerability under climate change remain relevant under the nexus perspective. Finally, the regulatory framework governing the Brazilian power sector has to be adjusted as these sources increase their participation in the mix.

Ultimately, future developments on energy law and policy shall promote closer integration amongst energy, environment, and climate change. The methodology adopted in this paper builds up in that regard by informing, through scenarios that models these interactions, the paths where energy law and policy may follow. Such approach will imply in more coherent and effective policy making, which will contribute to improve security throughout the energy-waterfood nexus.

\section{Acknowledgements}

This article is part of the BRIDGE project by framing the boundaries of the Brazilian Nexus. BRIDGE (http://bridgeproject.net) is funded by the Newton Fund, a collaboration between the Brazilian FAPESC and the UK ESRC research councils, grant No. ES/N013174/1. This work started under the LINKS2015, project also funded by the Newton Fund (EPSRC and FAPESC), grant No. EP/N002504/1. Other funders include EPSRC and Horizon2020 (JFM; EP/K007254/1, 689150 SIM4NEXUS), CONICYT (PS), Philomathia Foundation (JEV) and Cambridge Humanities Research Grant scheme (JEV).

\section{References}

ANEEL, 2008. Atlas de energia elétrica do Brasil, 3rd ed, Agência Nacional de Energia Elétrica 
(ANEEL). Brasília-DF.

Barroso, L. a., Granville, S., Trinkenreich, J., Pereira, M.V., Lino, P., 2003. Managing hydrological risks in hydro-based portfolios. 2003 IEEE Power Eng. Soc. Gen. Meet. (IEEE Cat. No.03CH37491). https://doi.org/10.1109/PES.2003.1270395

Blomfield, A., Plummer, J., 2014. The allocation and documentation of hydrological risk. Int. J. Hydropower Dams 5 (5), 94-108.

Bradbrook, A.J., 1996. Energy Law as an Academic Discipline. J. Energy Nat. Resour. Law 14 (2), 193-217. https://doi.org/10.1080/02646811.1996.11433062

Brasil, 2015. Intended Nationally Determined Contribution towards achieving the objective of the United Nations Framework Convention on Climate Change (UNFCCC) [WWW Document]. Tech. report, Gov. Fed. Repub. Brazil, UNFCCC. Ministério do Meio Ambient. URL http://www.itamaraty.gov.br/images/ed_desenvsust/BRAZIL-iNDC-english.pdf (accessed 12.27.18).

Corrêa da Silva, R., Marchi Neto, I. De, Seifert, S.S., 2016. Electricity supply security and the future role of renewable energy sources in Brazil. Renew. Sustain. Energy Rev. 59, 328341. https://doi.org/10.1016/j.rser.2016.01.001

De Lucena, A.F.P., Clarke, L., Schaeffer, R., Szklo, A., Rochedo, P.R.R., Nogueira, L.P.P., Daenzer, K., Gurgel, A., Kitous, A., Kober, T., 2016. Climate policy scenarios in Brazil: A multi-model comparison for energy. Energy Econ. 56, 564-574. https://doi.org/10.1016/J.ENECO.2015.02.005

De Lucena, A.F.P., Szklo, A.S., Schaeffer, R., de Souza, R.R., Borba, B.S.M.C., da Costa, I.V.L., Júnior, A.O.P., da Cunha, S.H.F., 2009. The vulnerability of renewable energy to climate change in Brazil. Energy Policy 37 (3), 879-889. 
https://doi.org/10.1016/J.ENPOL.2008.10.029

de Souza Dias, V., Pereira da Luz, M., Medero, G., Tarley Ferreira Nascimento, D., de Souza

Dias, V., Pereira da Luz, M., Medero, G.M., Tarley Ferreira Nascimento, D., 2018. An

Overview of Hydropower Reservoirs in Brazil: Current Situation, Future Perspectives and

Impacts of Climate Change. Water 10 (5), 592. https://doi.org/10.3390/w10050592

EPE, 2017. Plano Decenal de Expansão de Energia 2026, Empresa de Pesquisa Energética

(EPE), Ministério de Minas e Energia (MME). Brasília-DF.

Heffron, R.J., Rønne, A., Tomain, J.P., Bradbrook, A., Talus, K., 2018. A treatise for energy law. J. World Energy Law Bus. 11 (1), 34-48.

Heffron, R.J., Talus, K., 2016a. The development of energy law in the 21st century: a paradigm shift? J. World Energy Law Bus. 9, 189-202.

Heffron, R.J., Talus, K., 2016b. The evolution of energy law and energy jurisprudence: Insights for energy analysts and researchers. Energy Res. Soc. Sci. 19, 1-10. https://doi.org/10.1016/j.erss.2016.05.004

INPE, 2006. Atlas Brasileiro de Energia Solar, INPE. https://doi.org/10.1007/s13398-014-01737.2

Inti Leal, F., Rego, E.E., de Oliveira Ribeiro, C., 2017. Levelized cost analysis of thermoelectric generation in Brazil: A comparative economic and policy study with environmental implications. J. Nat. Gas Sci. Eng. 44, 191-201. https://doi.org/10.1016/j.jngse.2017.04.017

Jonker, J.G.G., van der Hilst, F., Junginger, H.M., Cavalett, O., Chagas, M.F., Faaij, A.P.C., 2015. Outlook for ethanol production costs in Brazil up to 2030, for different biomass crops and industrial technologies. Appl. Energy 147, 593-610.

https://doi.org/10.1016/j.apenergy.2015.01.090 
Lambin, E.F., Meyfroidt, P., 2011. Global land use change, economic globalization, and the looming land scarcity. Proc. Natl. Acad. Sci. 108 (9), 3465-3472.

https://doi.org/10.1073/pnas.1100480108

Luomi, M., 2014. Sustainable Energy in Brazil - Reversing Past Achievements or Realizing Future Potential, OIES Papers. Oxford Institute for Energy Studies, Oxford, UK.

Magalhães, G., Tomiyoshi, L., 2011a. Electricity in Brazil-Part 1 [History]. IEEE Ind. Appl. Mag. (Column Ed. Erling Hesla) 17 (2), 8-12. https://doi.org/10.1109/MIAS.2010.939808 Magalhães, G., Tomiyoshi, L., 2011b. Electricity in Brazil—Part 2 [History]. IEEE Ind. Appl. Mag. (Column Ed. Erling Hesla) 17 (3), 8-69. https://doi.org/10.1109/MIAS.2011.940432 Maia, C., 2017. Déficit de energia vai custar R \$ 39 bilhões a hidrelétricas. Valor Econômico 08/05/2017.

Marengo, J.A., Tomasella, J., Alves, L.M., Soares, W.R., Rodriguez, D.A., 2011. The drought of 2010 in the context of historical droughts in the Amazon region. Geophys. Res. Lett. 38 (12), 1-5. https://doi.org/10.1029/2011GL047436

Mercure, J.-F., Paim, M.-A., Bocquillon, P., Lindner, S., Salas, P., Martinelli, P., Berchin, I.I., Guerra, J.B.S.O.A., Derani, C., De Albuquerque Junior, C.L., Ribeiro, J.M.P., Knobloch, F., Pollitt, H., Edwards, N.R., Holden, P.B., Foley, A., Schaphoff, S., Faraco, R.A., Viñuales, J., 2017. System Complexity and Policy Integration Challenges: the Brazilian EnergyWater-Food Nexus (No. 6), C-EENRG Working Papers. Cambridge, UK.

Mercure, J.-F., Pollitt, H., Edwards, N.R., Holden, P.B., Chewpreecha, U., Salas, P., Lam, A., Knobloch, F., Vinuales, J.E., 2018. Environmental impact assessment for climate change policy with the simulation-based integrated assessment model E3ME-FTT-GENIE. Energy Strateg. Rev. 20, 195-208. https://doi.org/10.1016/j.esr.2018.03.003 
Mercure, J.-F., Salas, P., 2013. On the global economic potentials and marginal costs of nonrenewable resources and the price of energy commodities. Energy Policy 63, 469-483. https://doi.org/https://doi.org/10.1016/j.enpol.2013.08.040

Mercure, J.-F., Salas, P., 2012. An assessement of global energy resource economic potentials. Energy 46 (1), 322-336. https://doi.org/https://doi.org/10.1016/j.energy.2012.08.018

Miller, G.T., Spoolman, S.E., 2012. Living in the environment, 17th ed. Brooks Cole, Canada.

Millington, N., 2018. Producing water scarcity in São Paulo, Brazil: The 2014-2015 water crisis and the binding politics of infrastructure. Polit. Geogr. 65, 26-34. https://doi.org/10.1016/j.polgeo.2018.04.007

MME, 2018. Boletim Mensal de Monitoramento do Sistema Elétrico Brasileiro [WWW Document]. Ministério Minas e Energia, Secr. Energ. Elétrica, Dep. Monit. do Sist. Elétrico. URL http://www.mme.gov.br/web/guest/secretarias/energiaeletrica/publicacoes/boletim-de-monitoramento-do-sistema-eletrico/boletins-2018 (accessed 12.27.18).

Nazareno, A.G., Laurance, W.F., 2015. Brazil's drought: Beware deforestation. Science (80-. ). 347 (6229), 1427. https://doi.org/10.1126/science.347.6229.1427-a

Oliveira, A. De, 2003. The political economy of the Brazilian power industry reform, in: Political Economy of Power Market Reform Conference, Program on Energy and Sustainable Development. Stanford University Press, Stanford, CA, pp. 1-58.

ONS, 2018. Sobre o SIN: o Sistema em números [WWW Document]. URL http://ons.org.br/paginas/sobre-o-sin/o-sistema-em-numeros (accessed 12.28.18). ONS, 2008. Submódulo 1.1. O Operador Nacional do Sistema Elétrico e os Procedimentos de Rede: visão geral. Brasil. 
Polito, R., Maia, C., 2017. Reforma do setor elétrico é bem recebida no mercado livre. Valor Econômico 12/05/2017 P.B2.

Prado, F.A., Athayde, S., Mossa, J., Bohlman, S., Leite, F., Oliver-Smith, A., 2016. How much is enough? An integrated examination of energy security, economic growth and climate change related to hydropower expansion in Brazil. Renew. Sustain. Energy Rev. 53, 11321136. https://doi.org/10.1016/j.rser.2015.09.050

REN21, 2017. Renewables 2017 Global Status Report. Paris, France.

Rose, S.K., Kriegler, E., Bibas, R., Calvin, K., Popp, A., van Vuuren, D.P., Weyant, J., 2014. Bioenergy in energy transformation and climate management. Clim. Change 123 (3), 477493. https://doi.org/10.1007/s10584-013-0965-3

Rubin, E.S., Azevedo, I.M.L., Jaramillo, P., Yeh, S., 2015. A review of learning rates for electricity supply technologies. Energy Policy 86, 198-218. https://doi.org/https://doi.org/10.1016/j.enpol.2015.06.011

Ruffato-Ferreira, V., da Costa Barreto, R., Oscar Júnior, A., Silva, W.L., de Berrêdo Viana, D., do Nascimento, J.A.S., de Freitas, M.A.V., 2017. A foundation for the strategic long-term planning of the renewable energy sector in Brazil: Hydroelectricity and wind energy in the face of climate change scenarios. Renew. Sustain. Energy Rev. 72, 1124-1137. https://doi.org/https://doi.org/10.1016/j.rser.2016.10.020

Santos, M.A. dos, Rodrigues, M.G., 1998. Environmental issues arising from the thermopower generation in Brazil. Energy Policy 26 (14), 1065-1070. https://doi.org/https://doi.org/10.1016/S0301-4215(98)00050-0

Schmidt, J., Cancella, R., Pereira, A.O., 2016. An optimal mix of solar PV, wind and hydro power for a low-carbon electricity supply in Brazil. Renew. Energy 85, 137-147. 
https://doi.org/https://doi.org/10.1016/j.renene.2015.06.010

Srinivasan, T.N., Gopi Rethinaraj, T.S., 2013. Fukushima and thereafter: Reassessment of risks of nuclear power. Energy Policy 52, 726-736.

https://doi.org/https://doi.org/10.1016/j.enpol.2012.10.036

Tolmasquim, M., 2012. Power sector reform in Brazil, 1st ed. Synergia Editora, Rio de Janeiro.

Viñuales, J.E., 2019. The International Law of Energy (forthcoming). Cambridge University Press, Cambridge, UK.

Watts, J., 2017. The Amazon effect: how deforestation is starving São Paulo of water. The Guardian. 28/11/2017.

World Energy Council, Wyman, O., 2010. Pursuing sustainability: 2010 Assessment of country energy and climate policy. London, UK.

Zemp, D.C., Schleussner, C.-F., Barbosa, H.M.J., Hirota, M., Montade, V., Sampaio, G., Staal, A., Wang-Erlandsson, L., Rammig, A., 2017. Self-amplified Amazon forest loss due to vegetation-atmosphere feedbacks. Nat. Commun. 8, 14681. 